\title{
$N 72-12742$
}

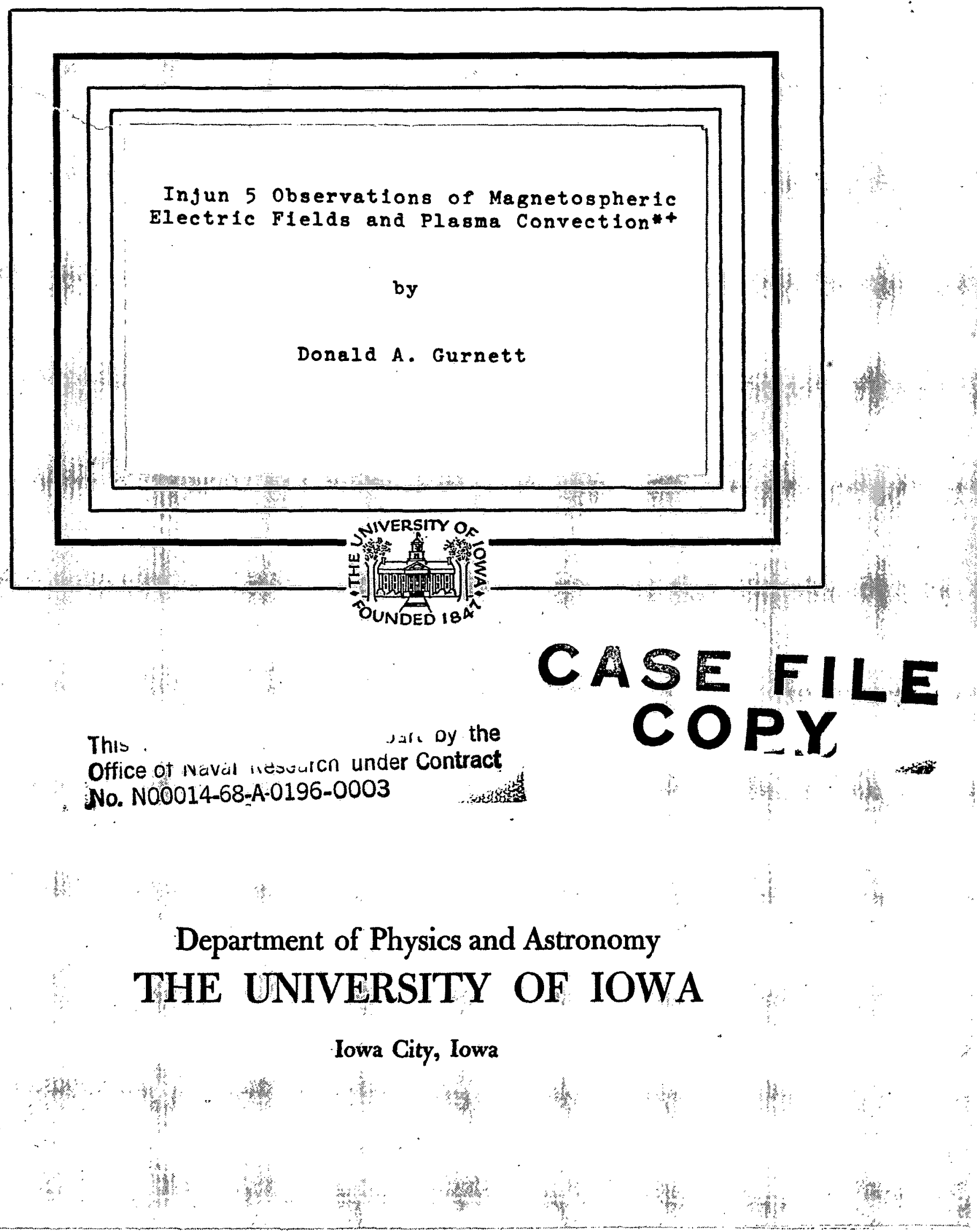


U. of Iowa 71-46

Injun 5 observations of Magnetospheric Electric Fields and Plasma Convection*t

by

Donald A. Gurnett

September 1971

Department of Physics and Astronomy

The University of Iowa

Iowa City, Iowa 52240

- Paper presented at the summer Adranced study Institute on Earth's Particles and Fields, Cortina, Italy, September 1971.

+Research supported in part by thè National Aeronautics and Space Administration under contracts NAS5-10625, NASI-8141, NASI-8144(f), NASI-8150(f), and NGL-16-001-043(97); and by the office of Naval Research under Contract No0014-68-A0196-0003. 
UNCLASSIFIFD

Sccurity Classificition

\section{DOCUMENT CONTROL DATA - R\&D}

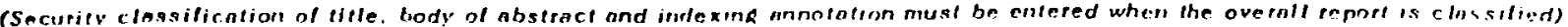

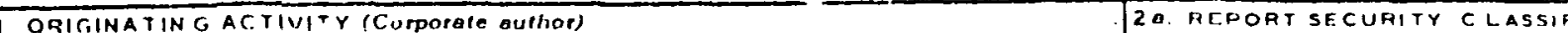

Department of Physics and Astronomy

University of Iowa UNCLASSIFIED

26 GROUP

3. REPORT TITLE

"Ingun 5 Observations of Magnetospheric Electric Fields and Plasma Convection"

4. DESCRIPTIVE NOTES (Type of reporl and inclusive dales)

Progress, September 1971

5. AUTHOR(S) (Last name. first name, initial)

Gurnett, Donald A.

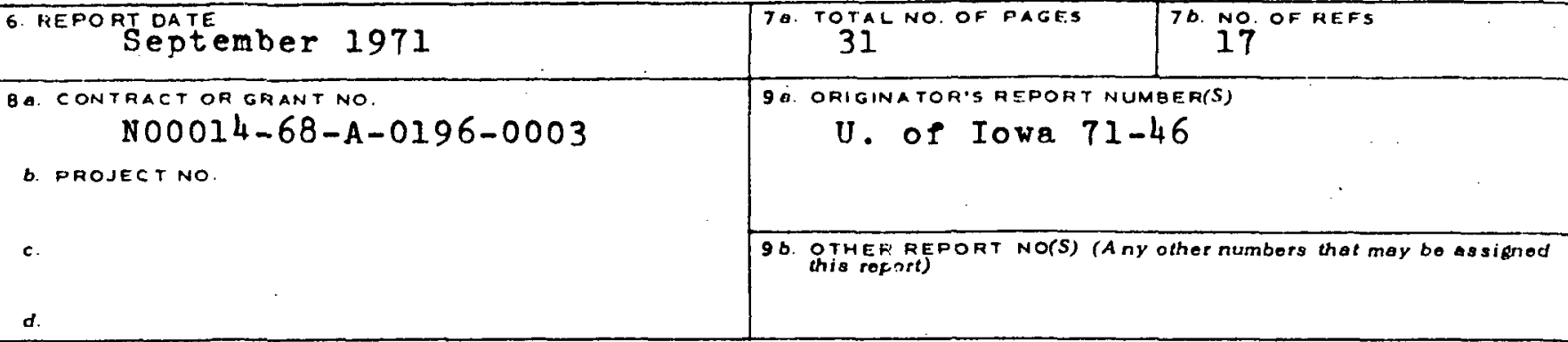

10. AVAILABILITY/LIMITATION NOTICES

Approved for public release; distribution is unlimited.

11. SUPPLEMENTARY NOTES

12. SPONSORING MILITARY ACTIVITY

Office of Naval Research

13. ABSTRACT

[See following page] 


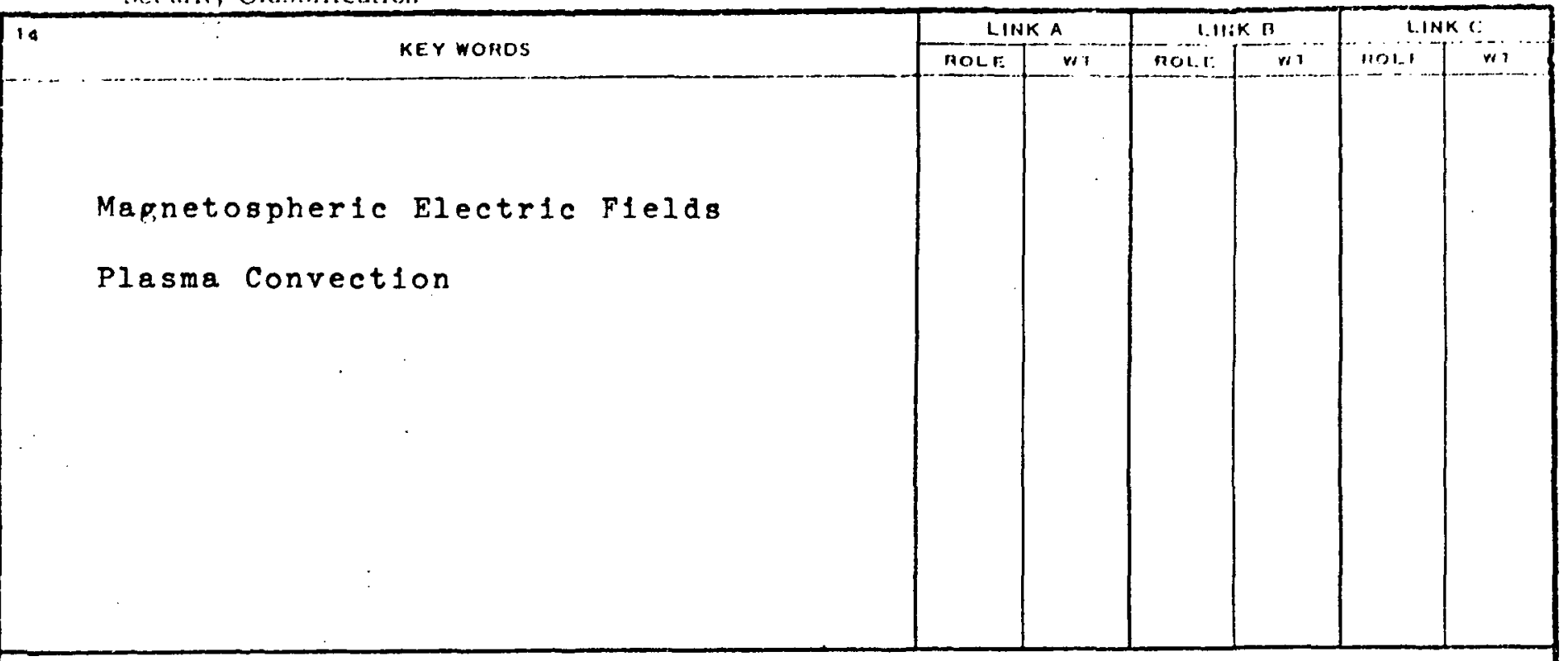

\section{INSTRUCTIONS}

1. ORIGINATING ACTIVITY: Enter the name and address of the contractor, subcontractor, grantee, Department of De fense activity or other organization (corporate author) issuing the report.

2a. REPORT SECURTY CLASSIFICATION: Enter the overall security classification of the report. Indicate whether "Restricted Data" is included Marking is to be in accordance with appropriate security regulations.

2b. GROUP: Automatic downgrading is specified in DoD Directive 5200.10 and Armed Forces Industrial Manual. Enter the group number. Also, when applicable, show that optional markings have been us ed for Group 3 and Group 4 as authorized.

3. REPORT TITLE: Enter the complete report title in all capital letters. Titles in all cases should be unclassified. If a meaningful title cannot be selected without classification, show title classification in all capitals in parenthesis immediately following the title.

4. DESCRIPTIVE NOTES: If appropriate, enter the type of report, e.g., int erim, progress, summary, annual, or final.

Give the inclusive dates when a specific reporting period is covered.

5. AUTHOR(S): Enter the name(s) of author(s) as shown on or in the report. Enter last name, first name, middle initial. If nilitary, show rank and branch of service. The name of the principal author is an absolute minimum requirement.

6. REPORT DATE Enter the date of the report as day, month, year; or month, year. If more than one date appears on the report, use date of publication.

7a. TOTAL NUMBER OF PAGES: The total page count should follow normal pagination procedures, i.e., enter the number of pages containing information

76. NUMBER OF REFERENCES. Enter the total number of references cited in the report.

8a. CONTRACT OR GRANT NUMBER: If appropriate, enter the applicable number of the contract or grant under which the report was written.

$8 b, 8 c, 8 d 8 d$. PROJECT NUMBER: Enter the appropriate military department identific ation, such as project number. subpruject number, system numbers, task number, etc.

9a. ORIGINATOR'S REPORT NUMBER(S): Enter the offirial report number by which the document will be identified and controlled by the originating activity. This number must be unique to this report.

9b. OTHER REPORT NUMBER(S): If the report has been assigned any other report numbers (either by the originator or by the sponsor). also enter this number(s).

10. AVAILABILITY/LIMITATION NOTICES: Enter any limitations on further dissemination of the report, other than those imposed by security classification, using standard statements such as:

(1) "Qualified requesters may obtain copies of this report from DDC"

(2) "Foreign announcement and dissemination of this report by DDC is not authorized."

(3) "U. S. Government agencies may obtain copies of this report directly from DDC. Other qualified DDC users shall request through

(4) "U. S. military agencies may obtain copies of this report directly from DDC. Other qualified users shall request through

5) "All distribution of this teport is controlled Qualified DDC users shall request through . $"$

If the report has been furnished to the Office of Technical Services, Department of Commerce, for sale to the public, indicate this fact and enter the price, if known

11. SUPPLEMENTARY NOTES: Use for additional explanatory notes.

12. SPONSORING MILITARY ACTIVITY: Enter the name of the departmental project office or laboratory sponsoring (pay ing for) the research and development. Include address.

13. ABSTRACT: Enter an abstract giving a brief and factual summary of the document indicative of the report, even though it may also appear elsewhere in the body of the technical report. If additional space is required, a continuation sheet sha!l be attached.

It is highly desirable that the abstract of classified reports be unclassified. Each paragraph of the abstract shall end with an indication of the military security classification of the in formation in the paragraph, represented as (TS). (S), (C), or (U).

There is no limitation on the length of the abstract. How. ever, the suggested length is from 150 to 225 words.

14. KEY WORDS: Key words are technically meaningful terms or short phrases that characterize a report and may be used as index entries for cataloging the report. Key words must be selected so that no security classification is required. Identi. fiers, such as equipment model designation, trade name, militan project code name, geographic location, may be used as key words but will be followed by an indication of technical con. text. The assignment of links, rales, and weights is optional. 
ABSTRACT

Recent measurements of magnetospheric electric fields with the satellite Injun 5 have provided a comprehensive global survey of plasma convection at low altitudes in the magnetosphere. A persistent feature of these electric field observations is the occurrence of an abrupt reversal in the convection electric field at auroral zone latitudes. The plasma convection velocities assoclated with these reversals are generally directed east-west, away from the sun on the poleward side of the reversal, and toward the sun on the equatorward side of the reversal. Convection velocities over the polar cap region are normally less than those observed near the reversal region. The electric field reversal is observed to be coincident with the 'trapping boundary' for electrons with energies E>45 keV. Near local noon the region of anti-sunward convection poleward of the electric field reversal/trapping boundary corresponds to the low-altitude extension of the polar cusp plasma. Intense 'Inverted $V$ ' electron precipitation events associated with auroral arcs are also observed near and poleward of the electric field reversal/trapping boundary. These observations are discussed in terms of a current model of magnetospheric convection. 


\section{INTRODUCTION}

Recent measurements of electric fields using the double-probe technique on the low-altitude (677 to $2528 \mathrm{~km}$ ) polar orbiting satelite Infun 5 have provided the first extensive global survey of electric fields and plasma convection in the magnetosphere: In this paper we summarize the principal observational results from the electric field experiment on this spacecraft.

The electric field experiment on Infun 5 is of the double-probe type described by Fahleson [1967] and others. The probes used consist of two conducting spheres $20.3 \mathrm{~cm}$ in diameter mounted on booms with a center-to-center separation of 2.85 meters. The spacecraft is magnetically oriented by a bar magnet within the spacecraft such that the electric antenna axis is maintained approximately perpendicular $\left(2 \pm 10^{\circ}\right)$ to the geomagnetic fleld. The potential difference between the spheres is obtained from a high input impedance differential amplifier and is recorded along with other data by a tape recorder in the satellite so that global surveys of electric fields and other geophysical phenomena can be obtained. Varlous other parameters such as the antenna impedance and the electron density and temperature are also avallable to determine if the electric antenna system is operating properly. For further 
detalls on the Infun 5 electric field instrumentation and observations the reader is referred to papers by Gurnett et al. [1969], Gurnett [1970], Caupeman and Gurnett [1971, 1972], and Frank and Gurnett [1971]. 


\section{DATA ANALYSIS AND INSTRUMENTAL EFFECTS}

Electric field measurements obtalned for a pass over the northern polar region are shown in Figure l to illustrate the technique used in analyzing the Injun 5 electric field data. The systematic sinusoidal variation evident in the measured electric field $E_{m}$, shown by the light line in the top panel of Figure 1 , is caused by the spacecraft rotation in the $\vec{V}_{s} \times \vec{B}$ field from the spacecraft motion through the lonosphere. At midde and low latitudes, where the fonospheric plasma 18 expected to corotate with the earth the $\vec{V}_{8} \times \vec{B}$ field provides a convenient reference for "callbrating" the overall accuracy of the electric field determination. After all instrumental effects are considered the overall accuracy of the Injun 5 " electric fleld measurements, as determined by comparisons with the $\vec{V}_{s} \times \vec{B}$ field, is about $\pm 30 \mathrm{mV} / \mathrm{m}$. This error is primerily caused by unequal photoelectron em18sion from the two spheres due to asymmetrical sunlight shadowing of the spheres by the supporting booms. For certain orlentations and for cases when the spacecraft is rotating very slowly, the effects of this asymmetrical shadowing can be eliminated and the accuracy is increased to about $\pm 10 \mathrm{mV} / \mathrm{m}$.

To determine naturally occurring convection electric flelds it is necessary to subtract the $\vec{V}_{8} \times \vec{B}$ field and errors 
due to shadowing asymmetries from the measured electric pield. The procedure used to determine the subtracted electric fleld, $E_{8}$, is to $(1)$ compute the expected $\vec{V}_{8} \times \vec{B}$ field component using the estimated spacecraft orientation (which is sometimes in error by up to $10^{\circ}$ in rotation about the geomagnetic field), and then to (2) readust the amplitude and phase of the sinusoldal $\vec{V}_{8} \times \vec{B}$ variations to provide a good fit to the observed $\vec{V}_{8} \times \vec{B}$ field at low latitudes where no convection electric fields are expected. The solld dark curve shown in the top panel of Figure 1 is the subtracted electric fleld, $E_{s}$, determined in this manner. The difference between the measured electric field and the subtracted electric field, $E_{c}=E_{m}-E_{s}$, is the best estimate of the actual convection electric field in the lonosphere. Other readily recognizable errors due to sunlight shadowing by the spacecraft body and wake effects must also be eliminated from consideration. See Caufman and Gurnett [1972] for a discussion of these effects.

The plasma convection velocity $\vec{\forall}_{c} 18$ determined from the convection electric field to using the equation [Axford, 1969]

$$
\vec{V}_{c}=\vec{E}_{c} \times \vec{B} / B^{2}
$$

The convection velocity components corresponding to the electric field measurements in the top panel of Figure 1 are shown by the arrows in the invariant latitude (INV) - magnetic local time (MLT) polar diagram at the bottom of Figure 1. The direction 
of the arrow represents the direction of the convection velocity component detected and the length of the arrow is proportional to the magnitude of the convection velocity. Note that the arrows do not indicate the vector direction of the convection velocity. since only one component is measured. 


\section{SUMMARY OF OBSERVATIONS}

The convection observations shown in Figures 2 and 3 have been selected to illustrate some of the general features of the Injun 5 convection electric fleld measurements. The most prominent and persistent feature of the Ingun 5 electric field data is the occurrence of an abrupt reversal or discontinuity in the convection electric field at about $70^{\circ}$ to $80^{\circ}$ invariant latitude. An example of such an electric field reversal is shown in Figure 1 at 1132 UT where the convection electric field changes sign, from about $-100 \mathrm{mV} / \mathrm{m}$ to $+125 \mathrm{mV} / \mathrm{m}$. The corresponding convection velocity component, shown in the polar diagram at the bottom of flgure 1, shows a reversal from eastward (sunward) flow on the equatorward side of the reversal to westward (ant1-sunward) flow on the poleward side of the reversal. The series of successive dawn-dusk polar passes 1llustrated in Figure 2 also shows simllar abrupt reversals in the direction of the convection velocity. These reversals are particularly evident in the dawn local time region at about $1724: 20,1925: 30$, and 2123:30 UT. Smaller reversals are also evident in the dusk region at 1734:00 and 2132:00 UT. In all cases the reversals are consistent with a generally sunward flow on the equatorward side of the reversal and anti-sunward flow on the poleward side of the reversal. 
Usually the largest convection velocities are observed near, within $5^{\circ}$ to $10^{\circ}$ invariant latitude, the electric field reversal location. At higher latitudes, in the polar cap region, the convection velocity is usually less than the 20.75 $\mathrm{km} / \mathrm{sec}$ sensitivity IImit imposed by the $\pm 30 \mathrm{mV} / \mathrm{m}$ uncertainty in the convection electric fleld determination. Orbit 6909 , in Figure 2, however shows the occurrence of an essentially uniform anti-sunward flow with velocities greater than $1 \mathrm{~km} / \mathrm{sec}$ along the entire satelilte trajectory over the polar region from 1724:00 to $1734: 00$ UT. Examples of relatively unf form transpolar convection, such as might be inferred from cases like orbit 6909 , with convection velocities greater than $0.75 \mathrm{~km} / \mathrm{sec}$ are not commonly observed with Ingun 5 .

Figure 3 illustrates the electric fleld observed for an approximately noon-midnight meridonal pass over the southern hemisphere. Near local noon, at about 0850:20 UT and $80^{\circ}$ INV, a clearly defined electric fleld reversal is observed. Over the polar cap region, from about 0852:00 to 0857:00, the convection velocity component detected is very small, less than $0.25 \mathrm{~km} / \mathrm{sec}$. The spacecraft orientation and rotation rate for this pass are such that the convection velocity can be determined to within about $0.25 \mathrm{~km} / \mathrm{sec}( \pm 10 \mathrm{mV} / \mathrm{m})$. In the local midnight region a large westward (anti-sunward) convection zone 1s observed from 0857:00 to 0902:00 UT and a variety of more complex variations is observed after 0902:00 UT: In this 
case, no discernible electric field reversal is observed in the local midnight region. The Injun 5 electric field observations through the noon-midnight local time regions generally tend to be more complex and less ordered than in the dawn-dusk regions, particularly near local midnight, with a tendency for multiple zones of convection and more than one electric field reversal or, as in the case shown, no electric field reversal at all.

In order to obtain a general ldea of the arerage or "typical" high latitude convection pattern a study was performed [Cauffman and Gurnett, 1972] using all of the available Ingun 5 electric field data. Since only one component of the electric field is sensed it is necessary to utilize a large number of observations at different antenna orfentations to deduce the general direction of the plasma flow. The method used to determine the general direction of the plasma flow was to analyze all of the observed electric field reversals in terms of either east-west or north-south velocity components on elther side of the reversal. Figure 4 shows the results of interpreting all of the observed reversals in terms of eastwest convection. Each point represents the position of an electric fleld reversal. The open circles indicate that the convection velocity is eastward on the poleward side of the reversal and westward on the equatorward side of the reversal. The dark circles ladicate the opposite, westward on the 
poleward side and eastward on the equatorward side. The half dark circles represent cases where the electric antenna orientation was such that only the north-south component of the convection velocity could be sensed.

From Figure 4 it is seen that for local times from 0 to 12 hours the convection velocity is generally westrard (antisunward) on the poleward side of the reversal and eastward (sunward) on the equatorward side of the reversal. For local times from 12 to 24 hours the latitudinal variation is fust the opposite. A similar scatter plot obtained by analyzing all of the reversals in terms of north-south convection components shows no consistent ordering of the data, thereby indicating that the convection velocities at the reversal boundary are primarily east-west.

The general convection pattern deduced from the Infun 5 observations is 11lustrated schematicaliy in Figure 5. This diagram incorporates the results from the statistical study discussed above indicating that near the reversal the plasma flow is primarily east-west, away from the sun on the poleward side of the reversal, and toward the sun on the equatorward side of the reversal. The large arrows near the reversal boundary are indicative of the fact the largest convection velocities are usually observed within about $5^{\circ}$ to $10^{\circ}$ invariant latitude from the reversal boundary. The larger arrows in the dawn region compared to the dusk region are indicative of the fact that the convection velocities are usually largest in the dawn 
local time region [cf. Figure 2]. The narrowing of the arrows toward local noon is indicative of the fact that the latitudinal width of the convection zones tends to be narrower near local noon and wider in the local evening [cf. Flgure 3]. The smaller arrows over the polar cap region reflect the fact that the convection velocities are generally smaller ( $<0.75 \mathrm{~km} / \mathrm{sec})$ orer the polar cap region than near the reversal boundary. The anti-sunward direction of the convection in the polar cap region is based on the recent electric field measurements by Maynard [1971] with the OGO-6 satellite which reportedly show a general anti-sunward flow over the polar cap region with velocities generally below the $0.75 \mathrm{~km} / \mathrm{sec}$ sensitivity limit of the Ingun 5 electric field experiment.

It should be emphasized that the convection pattern lilustrated in Figure 5 represents a gross average of the convection detected by Injun 5 and significant departures undoubtedly occur. Since in many cases the convection velocity 1s below the sensitivity limit of the Ingun 5 electric field experiment, the convection pattern in Figure 5 represents conditions of enhanced conrection ( $>0.75 \mathrm{~km} / \mathrm{sec})$ and may not be representative of more quiescent conditions. 
IV. ASSOCIATION WITH CHARGED PARTICLE OBSERVATIONS

Comparisons of the low-energy charged particle measurements from the LEPEDEA instrumentation on Infun 5 and the electric field data have shown that the electric field reversal corresponds closely with the position of the 'trapping boundary' for electrons with energies E>45 keV [Frank and Gurnett, 1971]. (See Frank and Ackerson [1971a] for details of the LEPEDEA instrumentation.) An example of this association is 1llustrated in Figure 6 which shows the electric field and selected charged particle measurements for a dawn-dusk pass over the northern polar region. Because of the favorable antenna orientation and very slow rotation rate on this pass the convection electric field can be determined to an accuracy of about $\pm 10 \mathrm{mV} / \mathrm{m}$. A clearly deflned electric fleld reversal is observed at about 1443:20 UT in the dawn local time region and a smaller, less distinct, reversal is observed at about 1453:10 UT in the dusk local time region. These electric field reversals are seen to be essentially colncident with the high latitude termination of measurable intensities of electrons with energies $\mathrm{E}>45 \mathrm{keV}$ (indicated by the dashed vertical lines in Figure 6). This termination is commonly referred to as the 'trapping boundary' and represents a natural coordinate for investigating high latitude magnetospheric phenomena [see recent 
discussions by Frank and Ackerson, 1971b]. On the basis of these and other measurements, Frank and Gurnett [1971] have interpreted the trapping boundary and associated electric field reversal as delineating the high-latitude termination of closed field lines, with the sunward plasma flow occurring on closed field lines within the magnetosphere, and the antisunward plasma flow occurring on open fleld lines which connect Into the solar wind.

Low-energy electron precipitation events associated with auroral arcs are also observed near and sometimes poleward of the trapping boundary/electric field reversal location. These low-energy electron precipitation events often have a characteristic 'inverted $V$ ' energy-time signature with the average electron energy increasing from less than $100 \mathrm{eV}$ to a maximum of several keV, or more, subsequently decreasing as the satelifte passes through the precipitation region [Frank and Ackerson, 19710]. Inverted ' $V$ ' precipitation events have been directly associated with auroral arcs [Ackerson and Frank, 1971]. The low-energy, 3255Es570 ev, electron fluxes shown in the bottom panel of Figure 6 provide a coarse indication of the location of inverted ' $V$ ' electron precipitation events occurring during this pass. In the local morning region a single inverted ' $V$ ' event 18 observed at approximately 1443 UT, nearly colncident with the trapping boundary/electric field reversal location. In the local evening region two inverted 
'V' events are observed, one at about 1453 UT, near the trapping boundary, and the second at about 1452 UT, poleward of the trapping boundary.

The relative locations of the inverted ' $V$ ' events and the trapping boundary in this case are consistent with the general survey results of Frank and Ackerson [1971b] which show that the inverted ' $V$ ' precipitation events occur on open field lines near or poleward of the E>45 trapping boundary and in a region of generally anti-sunward convection [cf. Figure 5]. Equatorward of the E>45 keV trapping boundary, in the region of sunward convection, significant electron precipitation and associated auroral light emission are also observed during the local midnight and morning hours. However, the electron precipitation in this region generally has a harder energy spectrum and lower intensity than the inverted 'V' events and 1s Identifled by Frank and Ackerson [1971b] as originating from plasma sheet electrons injected onto closed field lines in the local midnight region.

Near local noon the convection electric fields observed by Infun 5 can be directly associated with the entry of magnetosheath plasma into the polar magnetosphere through the dayside polar cusp region ldentified by Frank [1971a], Frank and Ackerson [1971a], and Heikk1la and Winningham [1971]. An example of such on observation is shown in Figure 7 , from Gurnett and Frank [1972]. The intense Pluxes of low-energy electrons ( $325 \times \mathrm{E} \leq 570 \mathrm{eV})$ and protons (290<E<455 eV) occurring 
from 1511:30 to 1513:45 UT on this pass, poleward of the E>45 keV trapping boundary, identify this region as the polar cusp. The separation of the polar cusp into an equatorward electron sheet' and a poleward 'proton sheet' is directly comparable to Frank's [1971a] IMP-5 observations of the polar cusp at much higher altitudes, $\sim 5 \mathrm{R}_{E}$. The simultaneous observation of broad-band VLF hiss generated by the polar cusp plasma, shown in the top panel of Figure 7 , provides further evidence of the polar cusp location on this pass. The electric field data for this pass shows a negative perturbation from the $\vec{V}_{s} \times \vec{B}$ field of about $30 \mathrm{mV} / \mathrm{m}$ in the polar cusp region. This electric fleld corresponds to a westward (anti-sunward) convection of about $1 \mathrm{~km} / \mathrm{sec}$ in the polar cusp region. From this and other similar observations it is concluded that the polar cusp region is directly assoclated with the region of enhanced anti-sunward convection on the polerard side of the electric field reversal/ trapping boundary [cf. Figure 5]. 


\section{DISCUSSION}

The general pattern of low-altitude convection can be interpreted using the magnetospheric model shown in Figure 8 , from Frank and Gurnett [1971]. This model uses the process of merging of the geomagnetic fleld with the solar wind magnetic field proposed by Dungey [1961, 1968], along with the usual 'frozen field' model of plasma flow, to explain the coupling of the solar wind convection into agnetosphere, but differs from Dungey's model in the detalls of the flow over the polar cap region. Magnetic merging along the sunward surface of the magnetosphere allows the direct connection of geomagnetic field lines with the solar wind magnetic pleld. On the day side of the magnetosphere, these field ines constitute open field lines through the polar cusp, such as B and $b$ in Figure 8 , and provide for the direct entry of magnetosheath plasma to low altitudes within the magnetosphere. Since the plasma convection away from the sun on the day side of the magnetosphere is usually limited to a relatively narrow zone on the poleward side of the trapping boundary [cf. Figures 3 and 7 l the convective flow in the polar cusp region is believed to follow the east-west extension of the polar cusp into the dawn and dusk flanks of the magnetosphere as indicated in Figure 8. The width of this convection zone, which is inftially 
only a few degrees wide in invariant latitude near local noon, Increases considerably in the dawn and dusk regions. Subsequent anti-sunward convection carries the fleld lines into the distant plasma sheet (field lines $B^{\prime}$ and $b^{\prime}$ ) where they again merge to form closed field lines (such as A) in the near earth plasma sheet. The reader is referred to Frank [1971b] for a discussion of the various plasma regimes involved in this model. After merging occurs at the neutral sheet the fleld Iines are then convected sunward, toward the front of the magnetosphere (field line $A^{\prime}$ ) to complete the flow pattern. This flow pattern for magnetospheric plasma qualitatively accounts for the principal features of the observed convection pattern at low altitudes [ef. Figure 5]. It is to be noted that in this model the electric field reversal, which is the boundary between the reglons of sunward and anti-sunward flow, occurs on field Ines which are in the merging region. Since magnetic merging constitutes a basic process by which energy is dissipated within the magnetosphere, it is understandable that intense electron acceleration and precipitation are associated with the electric fleld reversals, although the detalls of these processes remain to be resolved. 


\section{ACKNOWLEDGMENTS}

This research was supported in part by the National Aeronautics and Space Administration under contracts NAS5-10625, NAS1-8141, NASI-8144(f), NASI-8150(f), and NGI-16-001-043(97); and by the office of Naval Research under Contract N00014-68-A0196-0003. 
Ackerson, K. L., and L. A. Frank, Correlated satellite measurements of low-energy electron precipitation and groundbased observations of a visible auroral arc, J.Geophys. Res. (submitted for publication), 1971.

Axford, W. I., Magnetospheric Convection, Reviews of Geophys., I. $421-459,1969$.

Cauffman, D.P., and D. A. Gurnett, Double-probe measurements of D.C. electric fields with the Injun 5 satellite, J. Geophys. Res., 77, 6014, 1971 .

Cauffman, D. P., and D. A. Gurnett, Satellite measurements of magnetospheric convection, Space Sci. Rev., (submitted for publication), 1972 .

Dungey, J.W., Interplanetary mapnetic fields and the auroral zones, Phys. Rev. Letters, 6, 47-48, 1961.

Dungey, J. W., The reconnection model of the magnetosnhere in Earth's Particles and Fields, (ed. B. M. McCormac), Reinhold Publishing Company, New York, 385-392, 1968.

Fahleson, U. V., Theory of electric field measurements conducted in the magnetosphere with electric probes, space Sci. Rev., I, 238-262, 1967 .

Frank, I. A., Plasma in the earth's polwar magnetosphere, J. Geophys. Res., T6, 5202-5219, 1971a.

Frank, L. A., Comments on a proposed magnetospheric model, J. Geophys. Res., 76, 2512-2515, 1971b.

Frank, L. A., and K. I. Ackerson, Observations of charged particle precipitation into the auroral zone, J. Geophys. Res., 76, 3612-3643, 1971 a.

Frank, L. A., and K. L. Ackerson, Local-time survey of plasma at low altitudes over the auroral zones, J.Geophys. Pes., (submitted for publication), 1971 b. 
Frank, L. A., and D. A. Gurnett, Distribution of plasmas and electric fields over the auroral zones and polar caps, J. Geophys. Res., 76, 6829-6846, 1971 .

Gurnett, D. A., Satelilte measurements of DC electric fields in the lonosphere, in Particles and Fields in the Magnetosphere, (ed. B. M. McCormac), D. Reidel Publishing Company, Dordrecht-Holland, 239-246, 1970 .

Gurnett, D. A., and L. A. Frank, VLF hiss and related plasma observations in the magnetosphere, J.Geophys. Res., (accepted for publication), 1972 .

Gurnett, D. A., G. W. Pfeiffer, R. R. Anderson, S. R. Mosier, and D. P. Cauffman, Initial observations of VLF electric and magnetic fields with the Ingun 5 satelite, J. Geophys. Res., 74, 4631, 1969 .

Heikkila, W. J., and J. D. Winningham, Penetration of magnetosheath plasma to low altitudes through the dayside magnetospheric cusps, J.Geophys. Res., 76, 883-891, 1971.

Maynard, N. C., Electric fields in the lonosphere and magnetosphere, presented at the Advanced study Institute on Magnetosphere-Ionosphere Interactions, Dalseter, Norway, Apri1 14-23, 1971 . 
FIGURES

Figure 1 Method of subtracting the $\vec{J}_{s} \times \vec{B}$ electric field, $E_{s}$, from the measured electric field, $E_{m}$, to determine the convection electric field, $E_{c}=E_{m}-E_{s}$, and a polar plot of the associated convection velocity component.

Figure 2 A series of dawn-dusk orbits showing the persistent occurrence of reversals in the convection electric field in both the dawn and dusk reglons, and one case (orbit 6909) having nearly constant antisunward convection along the entire satellite trajectory over the polar cap region.

Figure 3 A noon-midnight pass showing a dstinct reversal near local noon at about $80^{\circ}$ invariant latitude, relatively low convection velocities over the polar cap, and a large zone of westward convection in the local midnight region.

Figure 4 Locations of revergals observed by Injun 5, coded to indicate the east-west airection of the convection poleward and equatorward of the reversal. 
Figure 5 Qualitative sketch summarizing the 'average' convection pattern obtained from the Infun 5 electric field measurements.

Figure 6 Simultaneous electric fields and low-energy plasma measurements showing the correspondence between the electric field reversal, the E>45 keV trapping boundary, and inverted ' $V$ ' electron precipitation events.

Figuie 7 Simultaneous VLF, electric fleld and low-energy plasma observations showing the occurrence of anti-sunward (westward in this case) convection in the polar cusp region.

Figure 8 schematic digram showing the proposed model of magnetospheric convection. The electric field reversal and the $E>45 \mathrm{keV}$ trapping boundary occur at the boundary between open ( $B-b$ and $\left.B^{\prime}-b^{\prime}\right)$ and closed ( $A$ and $A^{\prime}$ ) fleld lines. 
i

ELECTRIC FIELD (mV/METER)

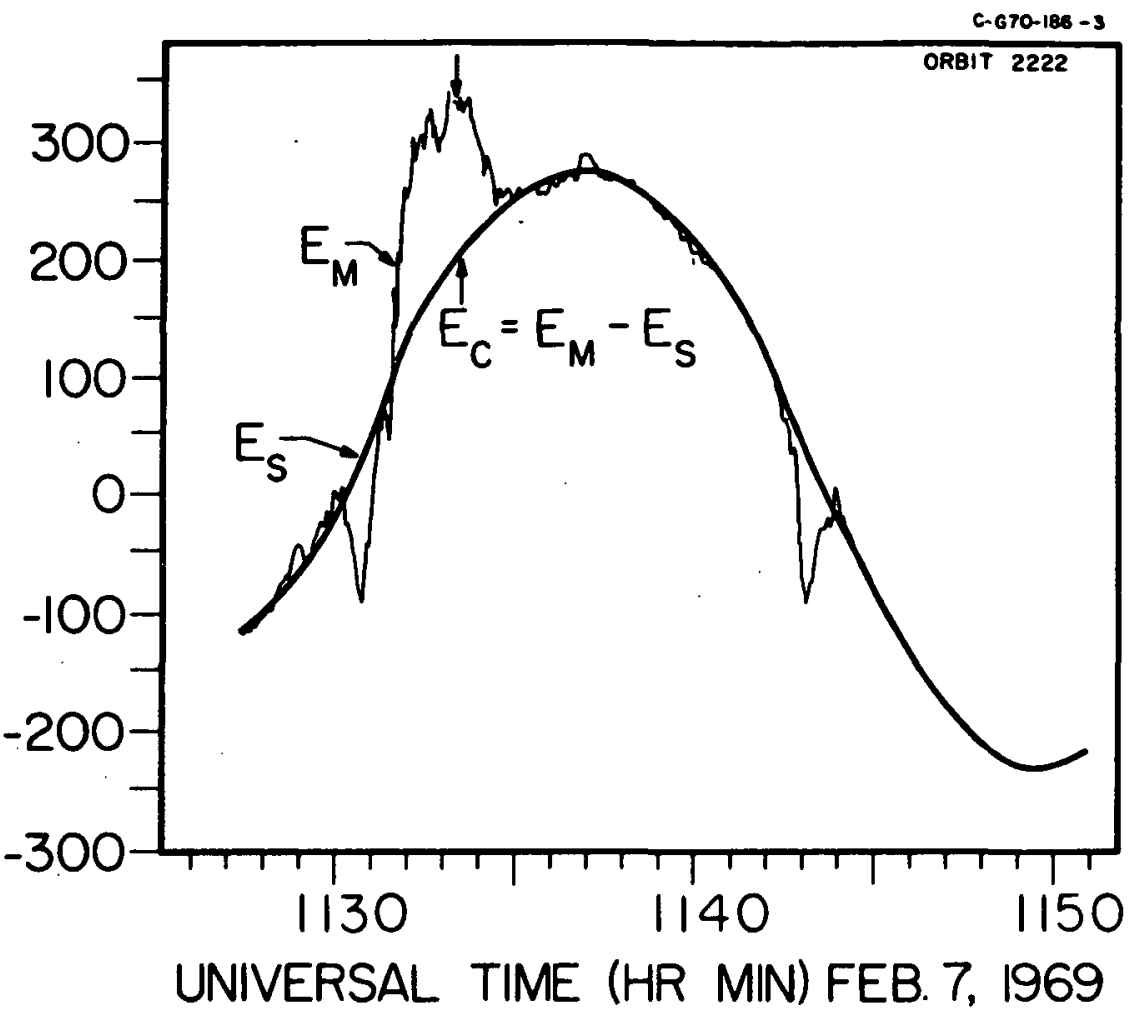

CONVECTION VELOCITY COMPONENT

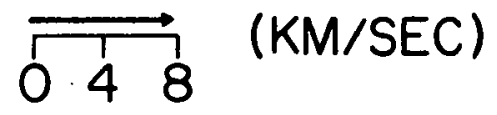

ANTENNA AXIS
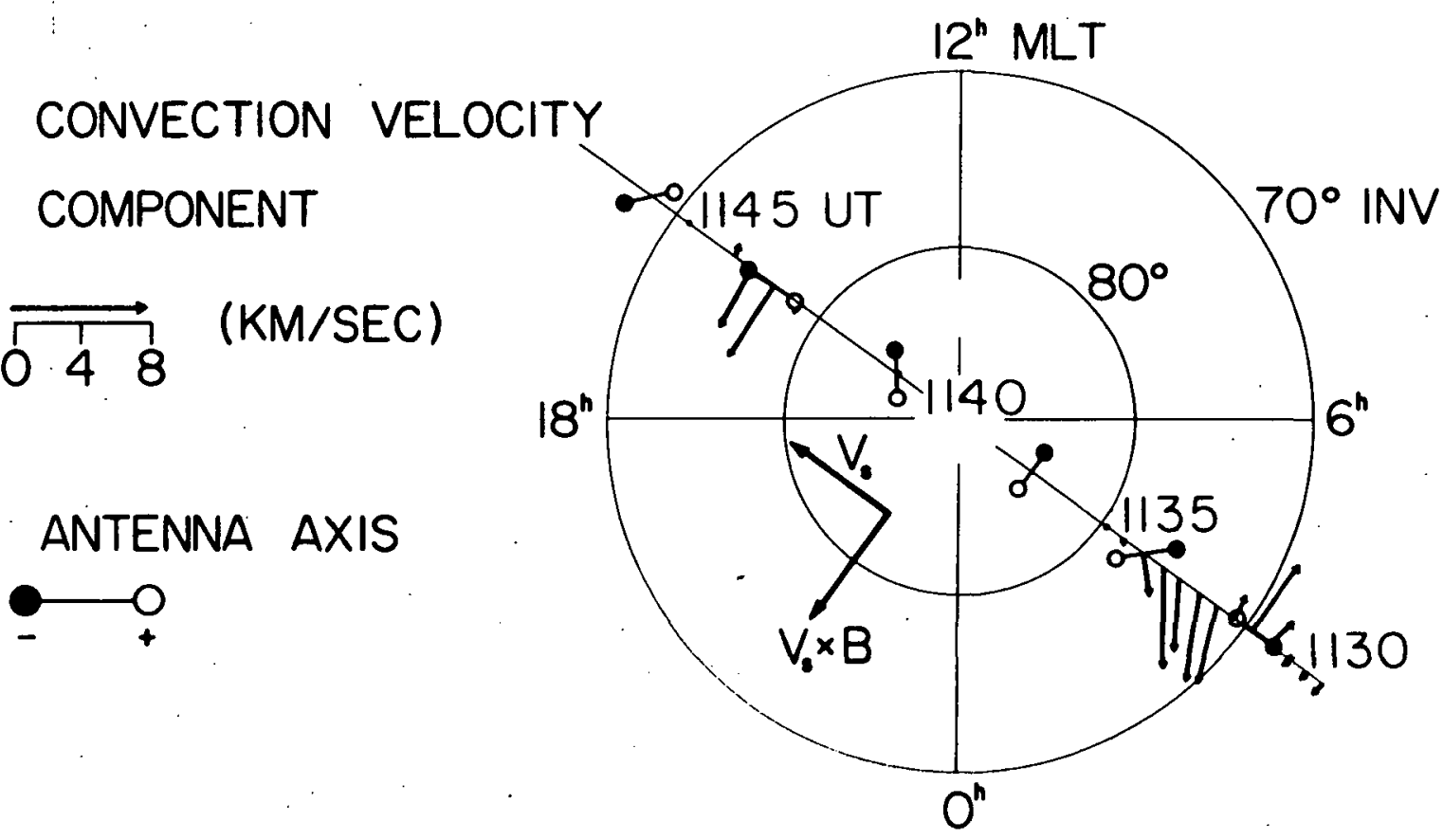

Figure 1 
ORBIT 6909

$K_{D}=1$

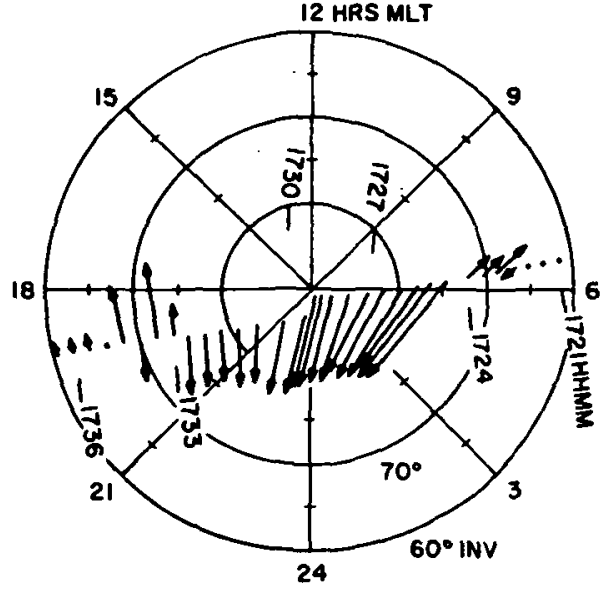

ORBIT 6910

$K_{P}=3$

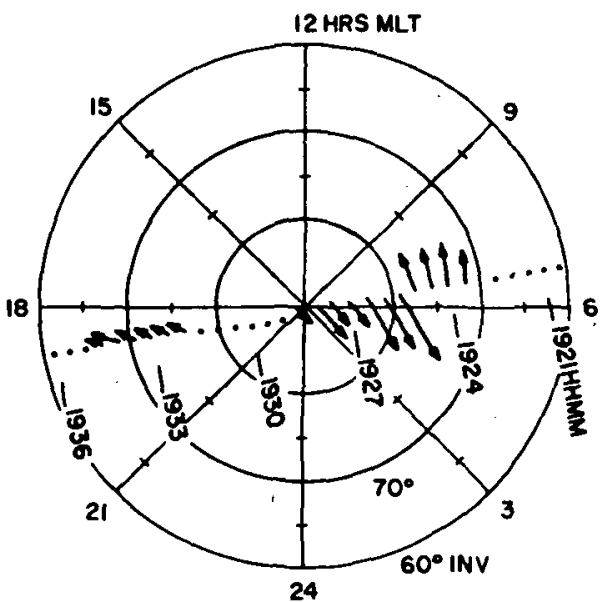

ORBIT 6911

$K_{p}=3$.

$K_{D}$ SUM $=31, D$

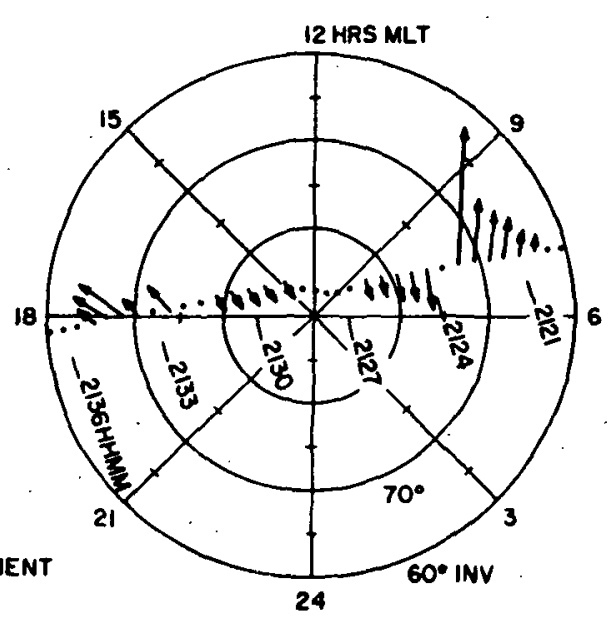

NORTHERN HEMISPHERE

FEBRUARY 27, 1970

ALTITUDE 700 KM

CONVECTION VELOCITY COMPONENT

KM/S

Figure 2 


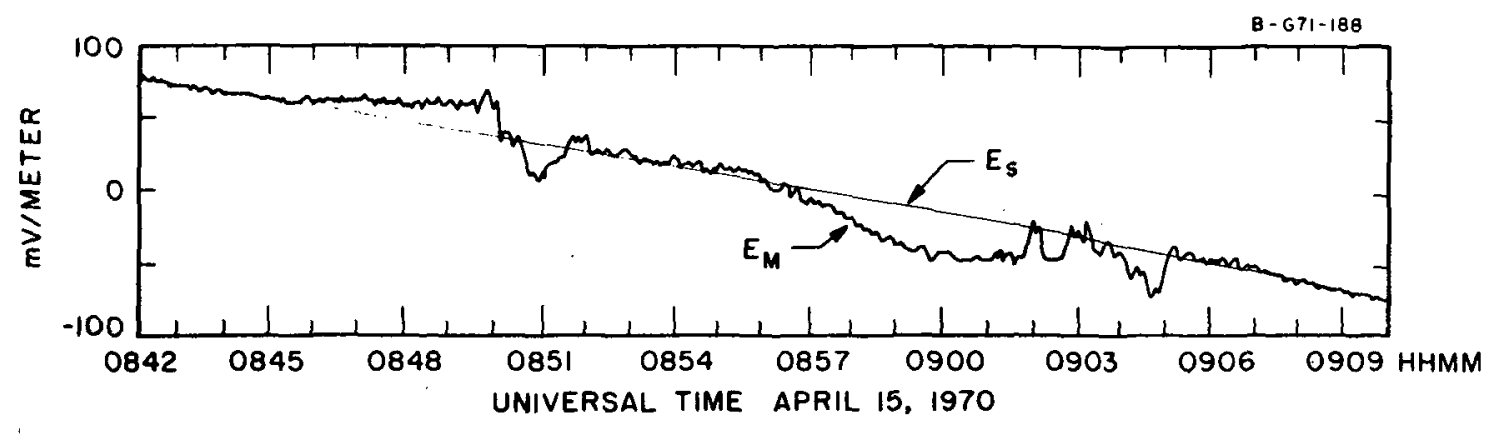

SOUTHERN HEMISPHERE ORBIT 7476 $K_{p}=1$

$K_{p} S U M=11-0$

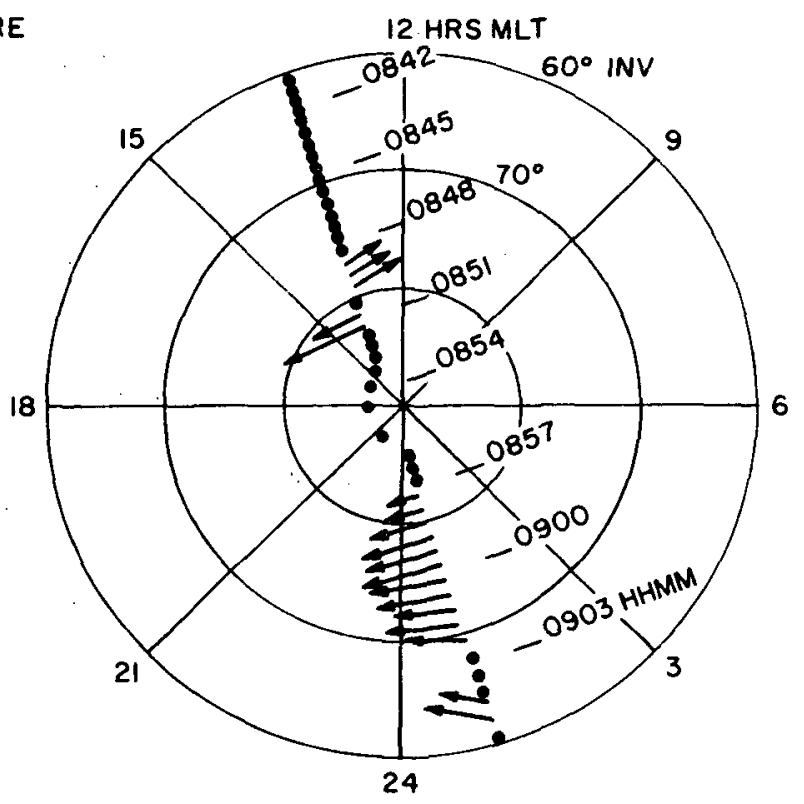

CONVECTION VELOCITY COMPONENT

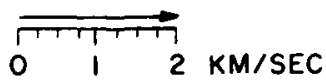

Figure 3 


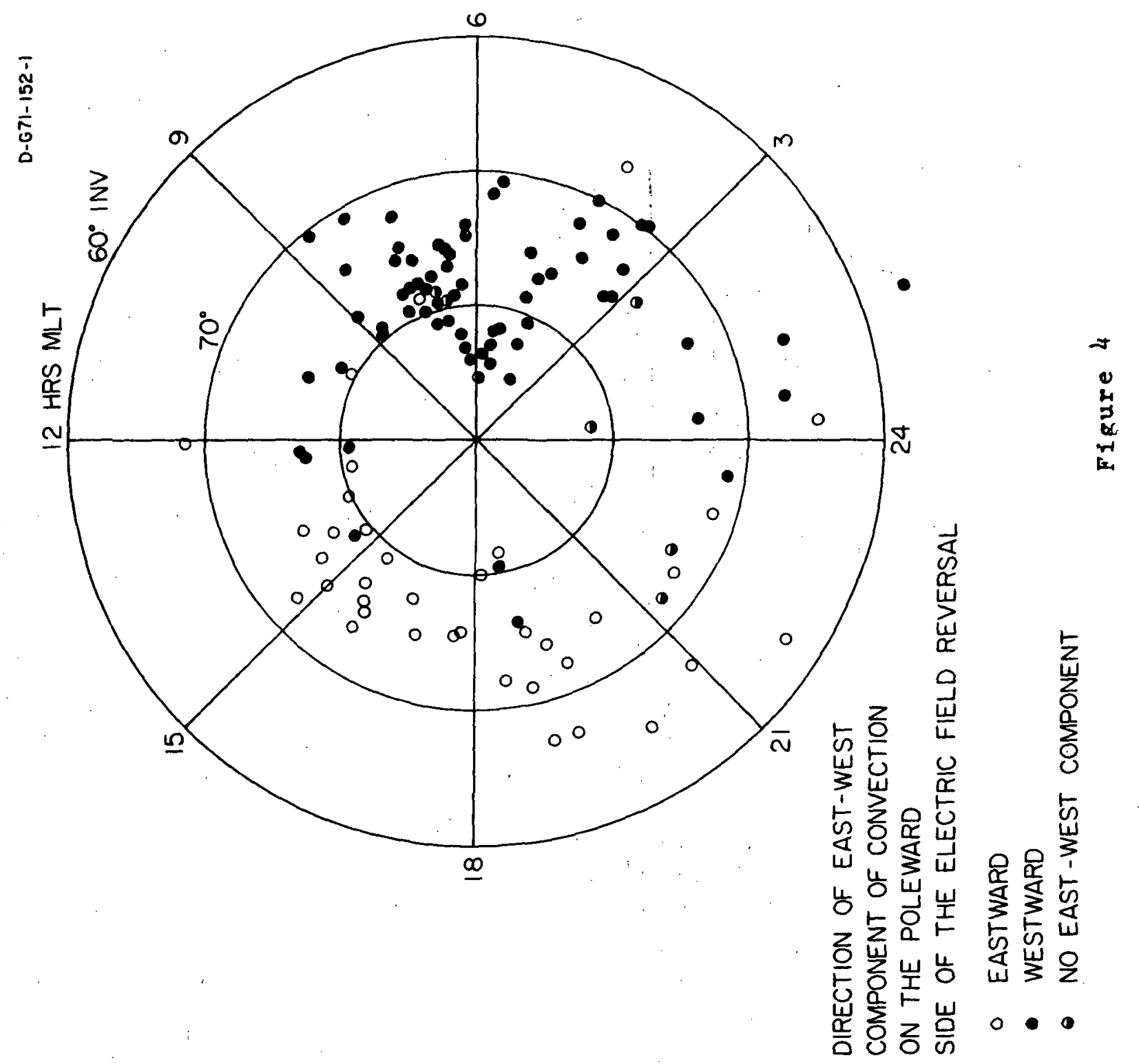




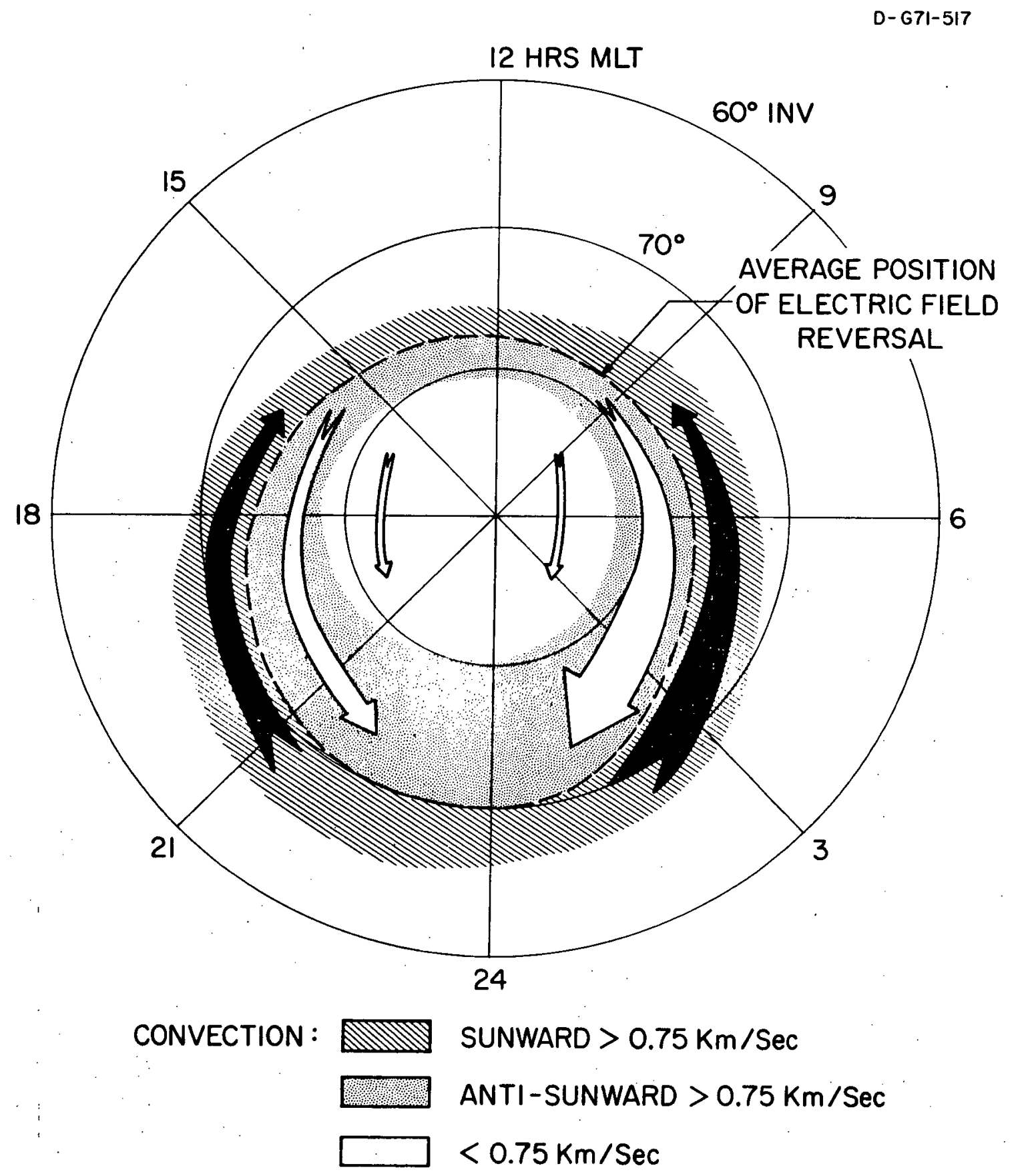

Figure 5 


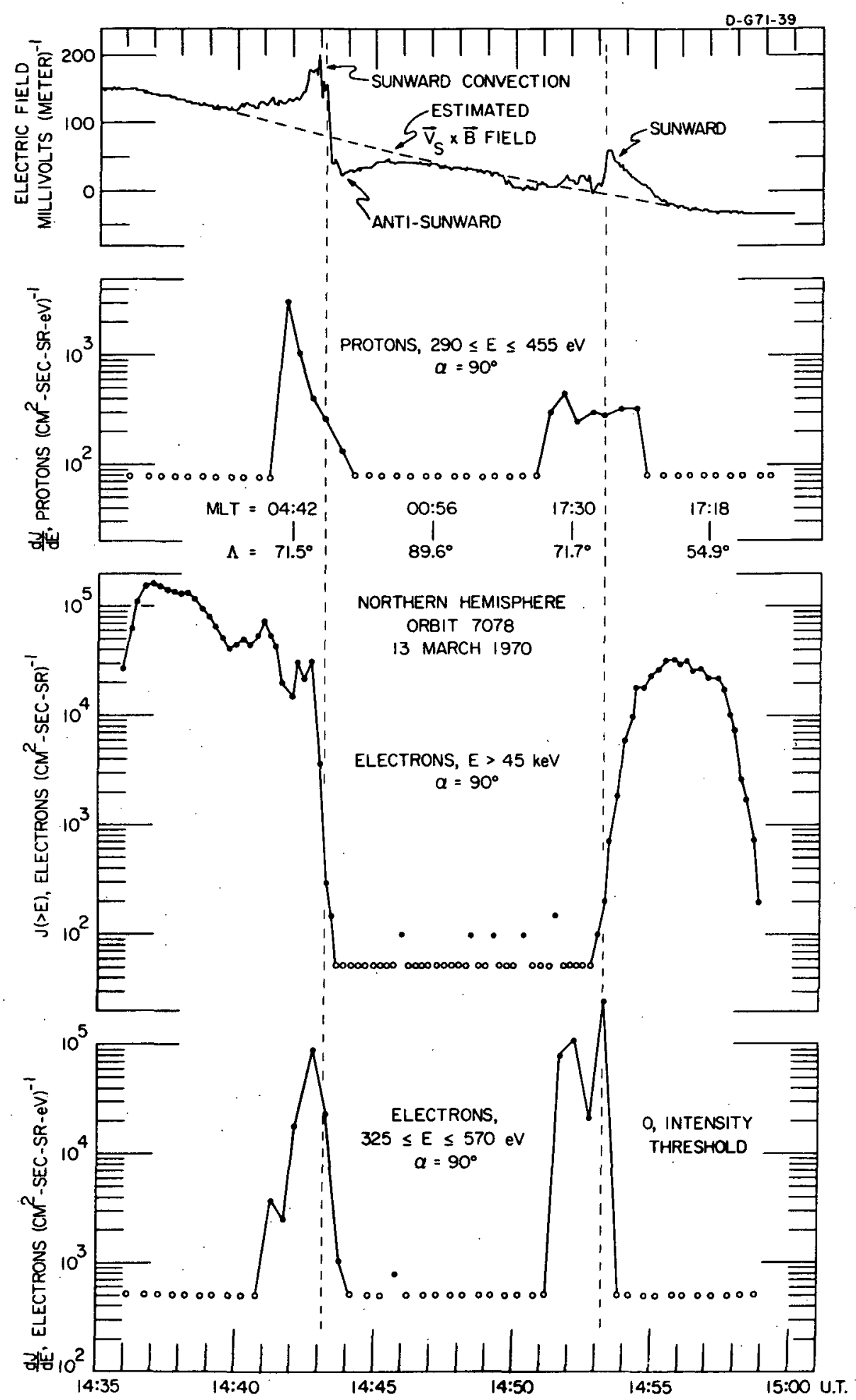

Figure 6 


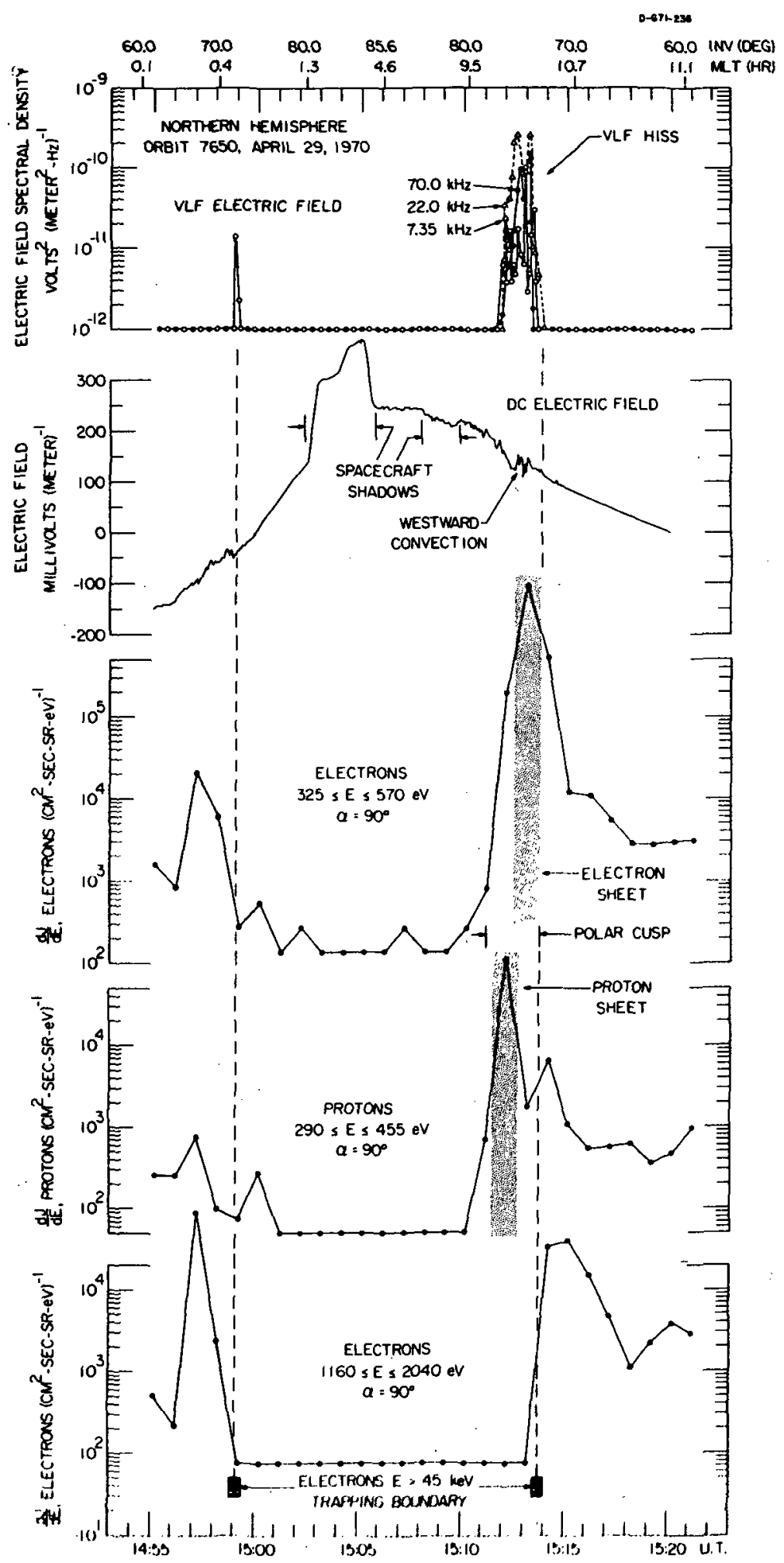



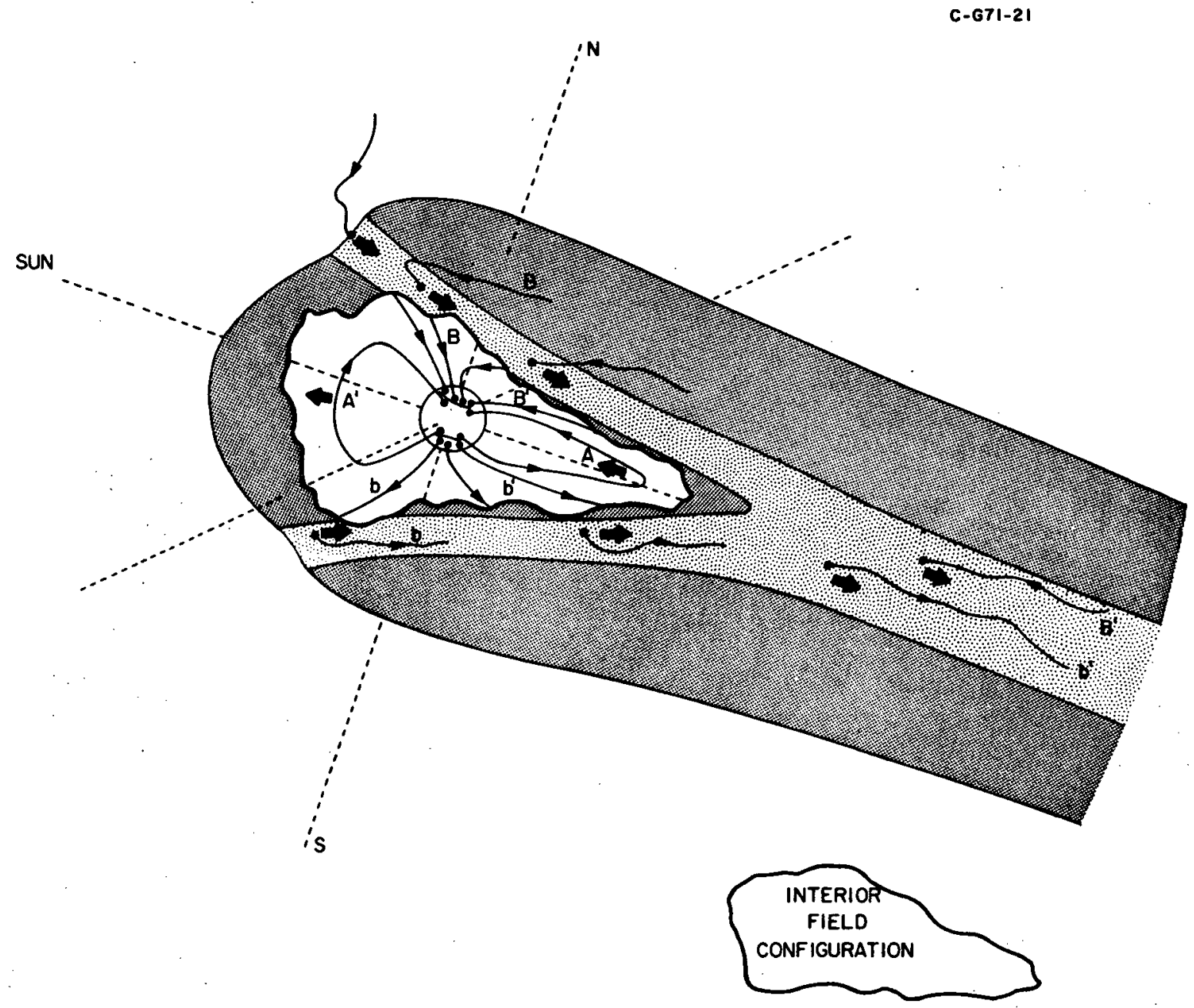

SCHEMATIC DIAGRAM FOR

MAGNETOSPHERIC AND LOW-ALTITUDE CONVECTION

(LOCAL EVENING, LOCAL MORNING)

MAGNETOPAUSE

ॠै POLAR CUSP, PLASMA SHEET AT MAGNETOPAUSE

$\rightarrow$ CONVECTION

Figure 8 